\title{
Scaling Jobs for the Poor: Reducing Poverty through the Impact Sourcing BPO Approach
}

\author{
Aneel Karnani \\ University of Michigan \\ Kevin McKague \\ Cape Breton University
}

Follow this and additional works at: https://digitalcommons.uri.edu/mgdr

Part of the Development Studies Commons, Economics Commons, Entrepreneurial and Small Business Operations Commons, International Business Commons, Nonprofit Administration and Management Commons, and the Other Business Commons

\section{Recommended Citation}

Karnani, Aneel and McKague, Kevin (2019) "Scaling Jobs for the Poor: Reducing Poverty through the Impact Sourcing BPO Approach," Markets, Globalization \& Development Review. Vol. 4: No. 4, Article 2. DOI: 10.23860/MGDR-2019-04-04-02

Available at: https://digitalcommons.uri.edu/mgdr/vol4/iss4/2

This Article is brought to you for free and open access by DigitalCommons@URI. It has been accepted for inclusion in Markets, Globalization \& Development Review by an authorized editor of DigitalCommons@URI. For more information, please contact digitalcommons-group@uri.edu. 
Scaling Jobs for the Poor: Reducing Poverty through the Impact Sourcing BPO Approach

\section{Markets, Globalization \& Development Review}
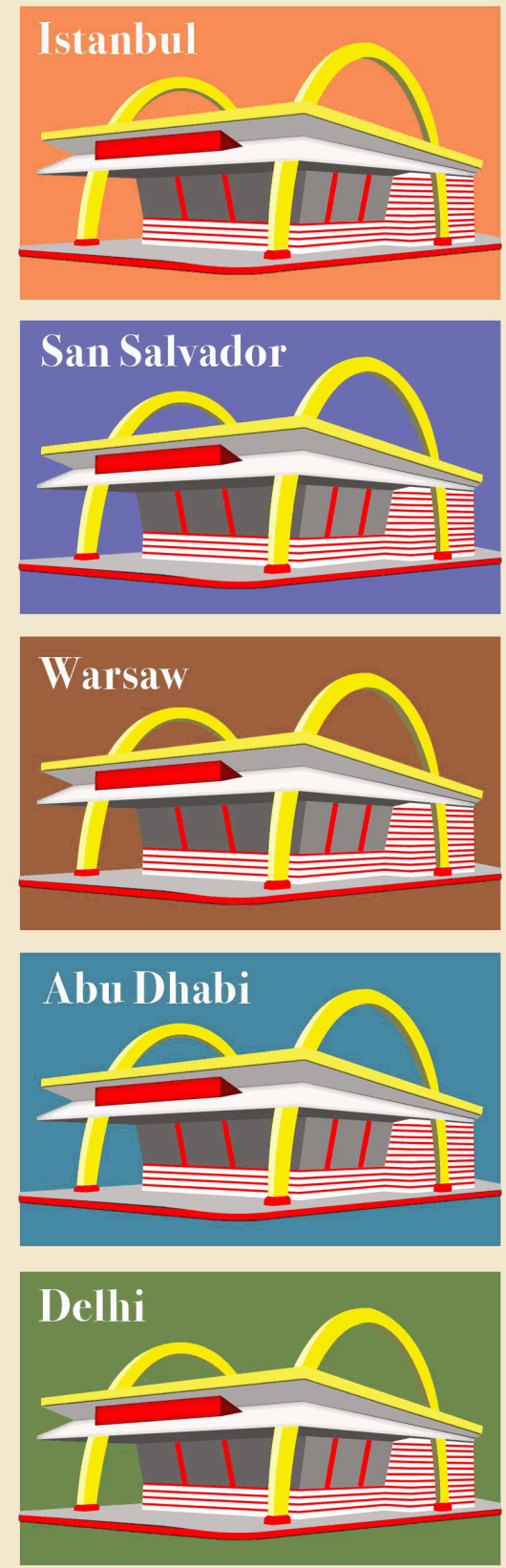
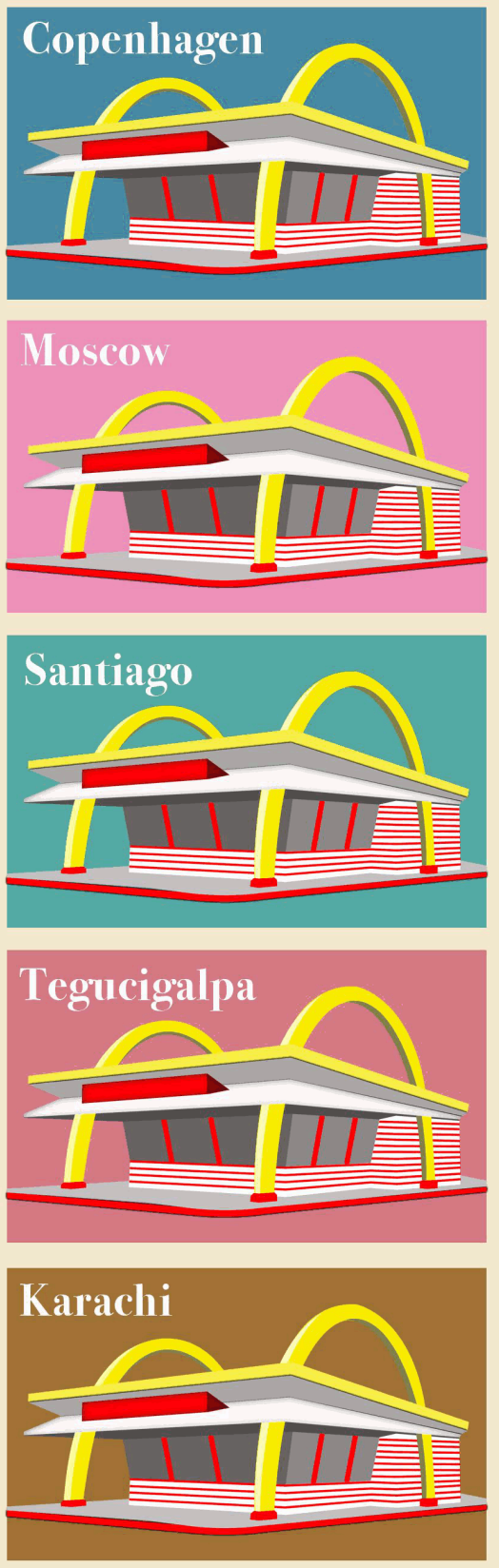
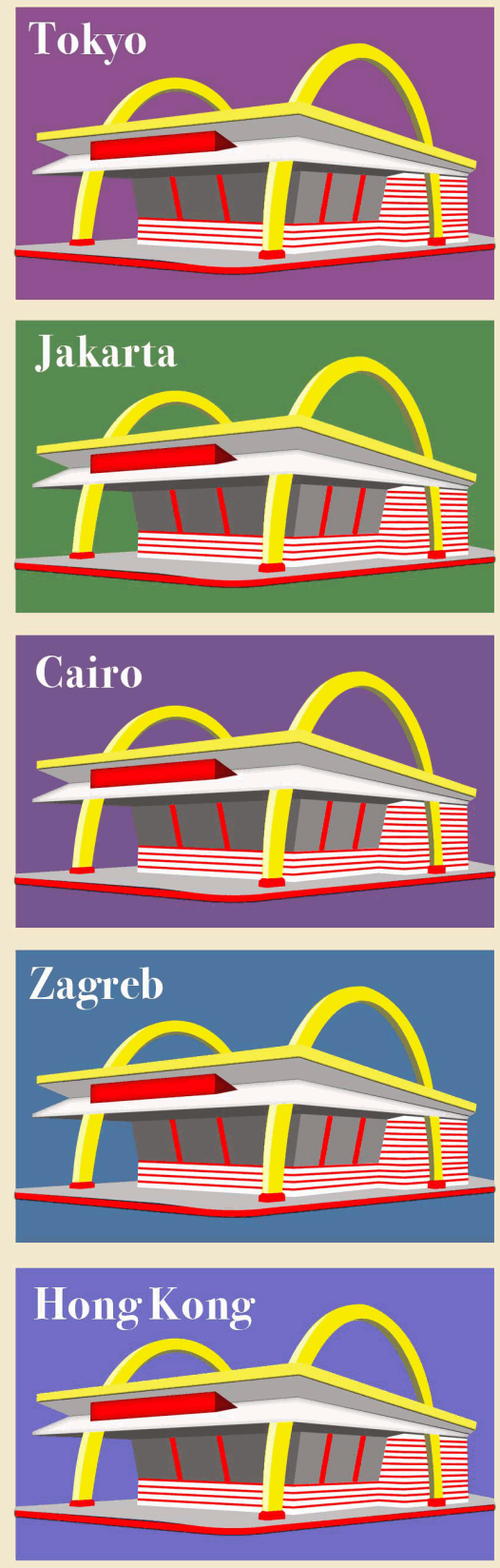

This article is available in Markets, Globalization \& Development Review: https://digitalcommons.uri.edu/mgdr/vol4/ 


\section{Scaling Jobs for the Poor: Reducing Poverty through the Impact Sourcing BPO Approach}

Widespread poverty is an urgent challenge for the world. The best way to alleviate poverty is to increase the income of the poor by providing productive employment. The International Labor Organization (ILO) states, "Nothing is more fundamental to poverty reduction than employment" (Karnani 2007: 38). It then argues vigorously for "decent" employment work that offers people a good income, security, flexibility, protection, and a voice on the job.

To reduce poverty through employment it is critical to create job opportunities appropriate to the skills of the poor, and to do this on a large scale. A whole variety of public policies and private strategies are needed to generate employment opportunities (McKague, Wheeler and Karnani 2015). One pragmatic approach is to focus on a sector of the economy that is employment-intensive and growing rapidly. A good candidate is business process outsourcing (BPO). BPO is outsourcing, to emerging economies, various non-core business processes that are informationand transaction-based.

\section{The Global Business Process Outsourcing Sector}

The business process outsourcing sector is expected to grow to $\$ 260$ billion by the end of 2020 (Global Industry Analytics 2017). BPO can be categorized into back-office outsourcing of internal business functions such as human resources, finance and accounting, and front-office outsourcing of customer-related services such as technical support. BPO clients include multinational firms and domestic companies as well as governments, universities and non-governmental organizations. Globally, the banking and financial services industries account for 50 percent of demand for BPO services, followed by the telecommunications and hightech sector at 22 percent and manufacturing at six percent (Kubzansky and Nyoro 2011). In terms of geography, North America accounts for 50 percent of BPO demand, followed by Europe at 30 percent and Asia at 15 percent (Kennedy et al. 2013).

Outsourcing of basic activities that are often based on information technology leads to efficiencies and cost savings. Besides reducing costs, BPO also increases a firm's flexibility by transforming fixed costs into variable costs and allowing the firm to focus on its core competencies. There are, of course, drawbacks to BPO such as failure to meet service 
levels, unclear contractual issues, increasing labor costs in emerging economies, and dependence on BPO vendors.

Companies and other organizations continually seeking the advantages of outsourcing propel the projected growth in the global BPO industry. Such advantages include the increasing cost benefits of outsourcing, improvements in information and communication technologies, the digitization of business processes, and cloud services that increasingly allow many activities to be outsourced quickly and cost effectively to lower-cost work centers around the world - especially to low-income countries. Leading centers for BPO include India, the Philippines, China, and South Africa.

Beginning in India with call centers, data entry and document transcription services (see, e.g., Kshetri and Dholakia 2011), the BPO industry has grown rapidly over the last two decades. As the early industry grew and matured in India, costs of labor and facilities began to rise in urban centers. Urban BPOs began offering higher value services such as research and engineering services. In response, new BPO centers were established in second-tier cities in India and in other middle- and lowerincome countries such as Kenya and the Philippines, where labor costs, facilities costs, and employee turnover were lower. Wages are the primary cost component in a BPO enterprise, impacting competitive pricing for the customer and margins for the service provider. BPOs based in smaller cities in India and in other low-cost countries picked up the lower-end outsourcing tasks such as digitization and scanning previously done by urban BPOs. These lower-end BPOs provided services directly to domestic and international clients, as well as to large higher-end BPOs that increasingly specialized in more value-added services. The impact sourcing segment is part of the lower-end BPO industry where organizations have an explicit mission to employ poor and disadvantaged workers.

As a country that has led job creation in the traditional BPO sector, India's experience shows the scale of job creation that can be achieved in a relatively short time (see, e.g., Kshetri and Dholakia 2009). Since its beginnings in the mid-1990s, India's BPO sector has created 3.5 million direct jobs and 10 million indirect jobs (NASSCOM 2015) and is expected to continue to grow at 15 percent per year (Kubzansky and Nyoro 2011). It is estimated that India could add an additional 10 million jobs in the BPO sector by the end of 2020 (Kennedy et al. 2013). Similarly, the Philippines and China have emerged as countries with mature BPO sectors that are expected to grow at 20 percent per year. 
According to some estimates, the global BPO sector has revenues of $\$ 147$ billion (Kennedy et al. 2013), employs 6 million people (Avasant 2012), and is growing at 10 percent per year (NASSCOM 2015). However, most BPO jobs require a high level of skills, education and language (usually English) literacy, and are not suited to the poor. But there is a segment of the BPO sector that requires a lower level of skills, such as data entry work, data verification and cleaning, scanning documents, and video tagging. "Impact sourcing" focuses on reducing poverty by providing BPO jobs to the poor. While this sounds promising, impact sourcing has in fact not delivered on its promise, at least not yet. We argue in this paper that impact sourcing is an initiative with much promise, and that to realize this promise at scale it is necessary to develop business models that focus on economic profitability. We illustrate our argument using longitudinal data on the three of the largest impact sourcing service providers.

\section{Reducing Poverty Through Employment}

Although poverty is a multidimensional concept, the most important problem for the poor is insufficient income to consume necessary food, shelter, health care, education and other essentials that would allow the achievement of a basic quality of life and wellbeing. The starting point for addressing the challenge of poverty is the simple and obvious observation that the best way to increase income is to provide opportunities for "decent" employment. Employment is not only the key source of income, it also enhances other dimensions of wellbeing, including technical skills, physical abilities, social skills and self-respect. Many of the current approaches to poverty reduction miss this simple point and do not emphasize employment opportunities.

Advocates of foreign aid believe that poor countries are caught in a "poverty trap" and need major injections of aid to trigger economic development (Sachs 2005; for a critique of this approach, see Dichter 2003 and Easterly 2006). But very little aid actually goes to stimulate enterprise development, even though private enterprise is well established as the best source of employment (World Bank 2013). The advocates of market liberalization as the best approach believe that free and open markets are the only vehicle for growing a nation out of poverty and that the "trickle down" effect will lead to poverty reduction. Globalization, however, has not brought the promised trickle-down benefits to many of the poorest people in the developing world. The problem with the exclusively free market approach is that it grossly underestimates the role of the government in economic development and poverty reduction (Friedman 2005; for a critique of this approach, see Chang 2008 and 
Stiglitz 2002). The "bottom of the pyramid" (BOP) approach argues that selling to the poor can simultaneously be profitable and eradicate poverty. The BOP approach is problematic because it views the poor primarily as consumers rather than as producers (Prahalad 2004; for a critique of this approach, see Karnani 2011). None of these approaches to poverty reduction has been successful. The foreign aid approach sees the poor as passive recipients of charity; the market liberalization approach sees the poor as automatic beneficiaries of a trickle-down effect; the BOP approach sees the poor as consumers. None of these approaches emphasizes directly increasing the productive capacity of the poor and providing them with job opportunities.

Similarly, although the microcredit movement aims to help the poor become self-employed, much recent research suggests that microcredit has not been effective at reducing poverty significantly (Banerjee, Karlan and Zinman 2015). The vast majority of microcredit clients are caught in subsistence activities and compete in crowded markets: they do not earn enough to rise out of poverty. Most microcredit clients are entrepreneurs by necessity and not by choice (Karnani 2007). Instead, to escape from poverty, the poor need productive jobs that lead to higher income.

The World Development Report on jobs reinforces the link between the creation of productive jobs and the reduction of poverty (World Bank 2012). In 2012, worldwide, 200 million people were unemployed. One hundred million people - fully one-half — are low-income individuals living under the $\$ 2 /$ day poverty line (McKague and Oliver 2012). The World Bank estimated in 2012 that 600 million new jobs would be needed globally by 2020 just to keep up with population growth. There is no magic solution for creating jobs on a large scale. Rather than discussing all the public policies and private strategies that can optimally generate employment, we argue for choosing a pragmatic, "good enough" approach: focus on a promising sector of the economy that has the potential to create jobs for the poor and suggest ways for organizations to do so effectively and at scale.

Business Process Outsourcing in general is a form of arbitrage that has helped development in developing and emerging economies like India. It has, however, tended to benefit the more educated upper and middle class urban employees in these countries. As an alternative, impact sourcing is about trying to bring these benefits to more disadvantaged, less educated and mostly rural populations. 


\section{Impact Sourcing}

Impact sourcing (also known as socially responsible sourcing or rural sourcing) is a niche segment of the BPO industry where organizations have an explicit mission to employ poor and disadvantaged workers. Impact sourcing organizations often target employing poor people with one or more labor market disadvantages such as their level of education, geographic location, social disadvantage (such as caste, gender or religion), or physical disability. Approximately 90 percent of the tasks that impact sourcing organizations undertake are working with data in some way; the remaining 10 percent of work comprises basic voice services such as domestic call centers. There are two types of impact sourcing organizations: not-for-profit and for-profit; both types espouse a social mission of employing poor and disadvantaged workers (see Table 1).

Table 1: Comparison of Traditional BPO and For-Profit and Not-forProfit Impact Sourcing Organizations

\begin{tabular}{|l|l|l|l|}
\cline { 3 - 4 } \multicolumn{1}{l|}{} & Traditional BPO & \multicolumn{2}{|l|}{ Impact Sourcing Organization } \\
\cline { 3 - 4 } \multicolumn{1}{l|}{} & Firm & For-Profit & Not-for-Profit \\
\hline Employees & $\begin{array}{l}\text { Educated, } \\
\text { urban, upper } \\
\text { and middle class }\end{array}$ & $\begin{array}{l}\text { Individuals disadvantaged in the } \\
\text { labor market due to geography } \\
\text { (rural), gender (women), socio- } \\
\text { economic status, or disability (deaf, } \\
\text { physically handicapped, etc.) }\end{array}$ \\
\hline $\begin{array}{l}\text { Geographic } \\
\text { Location }\end{array}$ & Large cities & Secondary cities and rural areas \\
\hline Return expected & Financial & $\begin{array}{l}\text { Social and } \\
\text { financial }\end{array}$ & Social \\
\hline $\begin{array}{l}\text { Strategy for } \\
\text { covering startup } \\
\text { losses }\end{array}$ & Can raise capital & Can raise capital & $\begin{array}{l}\text { Grants and } \\
\text { donations }\end{array}$ \\
\hline $\begin{array}{l}\text { Strategy for } \\
\text { covering } \\
\text { ongoing losses }\end{array}$ & $\begin{array}{l}\text { Reaching } \\
\text { breakeven and } \\
\text { profitability }\end{array}$ & $\begin{array}{l}\text { Reaching } \\
\text { breakeven and } \\
\text { profitability }\end{array}$ & $\begin{array}{l}\text { Grants and } \\
\text { donations }\end{array}$ \\
\hline $\begin{array}{l}\text { Potential to } \\
\text { scale }\end{array}$ & High & High & Low \\
\hline $\begin{array}{l}\text { Organizational } \\
\text { resilience and } \\
\text { continuity }\end{array}$ & High & High & Low \\
\hline
\end{tabular}


Impact sourcing makes efforts to create 'decent work' and good jobs that provide safe working conditions and incomes that are above average for the disadvantaged employees who work for these organizations. The nature of the BPO work is such that the working conditions (in office-like settings) are often much preferable to alternative employment opportunities such as manual labor in agriculture or construction. Since employees are locally based in the communities they work, their incomes are reinvested into their local communities with the goods and services they purchase. Many impact sourcing organizations are not-for-profit and reinvest their surplus (if any) in the local economies. The for-profit impact sourcing organizations are usually locally based and their surplus remains in the emerging country. These conditions allow impact sourcing to become an engine of poverty reduction through employment.

All firms in the BPO industry face the challenges of delivering services in a timely, confidential and secure way at a competitive cost. Additional challenges for impact sourcing organizations include: recruiting and training disadvantaged employees; achieving economies of scale; managing the increased complexities of a business with a social mission; unreliable infrastructure (especially in rural locations); and marketing services to company clients who may perceive greater risks to having work done by poor or disadvantaged people. Although the impact sourcing sector probably has the potential to grow at least as fast as the BPO sector globally (10-20\%), in 2020 the impact sourcing sector was still in the very early stages of development. It was growing much more slowly than the industry as a whole and not yet reaching its potential for creating productive jobs for workers from disadvantaged backgrounds (Kennedy et al. 2013).

Given the potential of the impact sourcing sector for reducing poverty, the Rockefeller Foundation has allocated almost $\$ 100$ million to understand how more impact sourcing jobs can be created in Africa. As part of its work, the Foundation has commissioned several reports. These studies consider the opportunity to create digital jobs in Africa (Harji et al. 2013), the value proposition for impact sourcing from the buyer's perspective (Bulloch and Long 2012), training models (Grimm et al. 2013), recruitment and impact measurement (de Abreu, Vilca and Bordeau 2013), and assessments of the potential for developing the impact sourcing sector in various countries (Avasant 2012; Dalberg 2013; Kennedy et al. 2013). Despite all this research, impact sourcing organizations have not been able to scale up and have a significant impact on employment opportunities. 


\section{Methodology}

In this paper, we chose to study the three largest impact sourcing organizations (by number of employees) in the world today: Samasource, Digital Divide Data (DDD), and RuralShores. For RuralShores, we collected primary data through visits to their head office and an operations center, as well as interviews with the CEO, top executives and employees. For the other two organizations - Samasource and DDD - we relied on publicly available information such as annual reports, IRS Form 990 filings, and existing literature. For all three organizations, we have longitudinal data from 2010 to 2017 (the latest comparable data available for all three organizations).

RuralShores is a for-profit impact sourcing organization, whereas the other two organizations are not-for-profit. We contrast the marketbased approach of RuralShores with the subsidy-dependent approach of Samasource and DDD and conclude that the only way impact sourcing can generate a significantly large number of jobs is by focusing on, and achieving, economic profitability. We then make suggestions for appropriate strategies for achieving profitability and impact at scale.

\section{Case Study 1: Samasource}

Operating out of San Francisco and Nairobi, Samasource is a non-profit organization founded by Leila Janah in 2008. Samasource markets its services to large companies in the USA. Using a proprietary technology platform, Samasource breaks large projects into small tasks they call microwork, which consists of computer-based tasks that can be completed by individuals with basic English skills and limited training. Samasource has built partnerships with ten local organizations in Haiti, India, Kenya and Uganda that recruit women and youth, provide two to four weeks of training in computer, English and soft skills (i.e., workplace norms and expected behaviour), and access to a computer.

While most recruits have no formal work experience, the majority have some degree of primary school education and basic English skills. Workers send and receive their microwork via the Internet. Samasource aggregates the completed microwork into final results and sends these to the client. Operations are performed through these local partner organizations, while sales and coordination functions are located in Samasource's San Francisco office. Samasource has experimented with running its own operations center, but they have decided to position themselves as a broker between large multinational clients and local impact sourcing organizations (Gino and Staats 2012). Samasource is a 
registered 501(c)(3) non-profit and has received financial support from a variety of charitable foundations.

\section{Case Study 2: Digital Divide Data}

Founded in 2001 as a non-profit by Jeremy Hockenstein and Michael Chertok, Digital Divide Data (DDD) was one of the first impact sourcing organizations. Hockenstein was a Canadian business consultant who, while traveling in Cambodia, recognized an opportunity to improve on the prevalent approach of computer schools that were graduating students without any connection to employment opportunities. Partnering with Chertok, DDD was established in Cambodia and developed a business that employs disadvantaged youth in digital jobs. DDD expanded to Laos in 2003 and Kenya in 2011.

DDD identifies and recruits disadvantaged youth, most with high school education, with limited access to job opportunities or an ability to pay for higher education. Recruits must demonstrate motivation and a willingness to learn. Recruits then undergo a training program focused on computer skills, English language and personal development, including the norms and soft skills needed to work in a formal business. After completing the training program, recruits work for DDD for a one-year probation period. If they continue to demonstrate motivation, employees become eligible for enrolling in college or university and for receiving a scholarship for half of their tuition from DDD. Work schedules are organized to allow employees to complete their post-secondary studies. DDD also helps workers apply for government student loans. In some cases, DDD pays the full cost of tuition up front and allows employees to pay back their 50 percent share through their earnings. Employees are required to "graduate" from employment at DDD after approximately five

years. DDD offers basic entry-level digital jobs, and after five years of work experience (and completion of a post-secondary degree), employees must seek employment at other organizations, although perhaps 10 percent of employees continue with DDD in management roles. To date, most of the capital for growth and expansion has come from philanthropic grants. DDD indicates that an effort to expand the number of disadvantaged youths it trains and hires has increased business expenses (Digital Divide Data 2013).

\section{Case Study 3: RuralShores}

RuralShores is a for-profit impact sourcing organization that focuses on employing workers in rural India (Mathew et al. 2009). Headquartered in Bengaluru (Bangalore), India, RuralShores employs 3,700 rural workers in 
18 operations centers across 10 Indian states. In 2020, clients of RuralShores included 42 national and international organizations from the corporate, government and non-profit sectors. Clients from the corporate sector include telecom companies, insurance companies and banks.

The labor market in India (and in most less-developed countries) suffers from low mobility and imperfect information (e.g., where job seekers often do not have enough information about available employment opportunities). Many rural people with some education, especially youth, face poor employment prospects in villages but still do not migrate to cities where job prospects might be better. This could be because they do not know how to look for an urban job, do not have the means to migrate to a city, or do not want to migrate for personal or cultural reasons. This suggests that impact sourcing organizations could establish facilities in rural areas and help create jobs there.

Besides a social mission, there is also an economic reason to establish rural facilities. The competitive intensity in the BPO sector has increased significantly with the sector's maturity, and profit margins have declined in recent years. To exacerbate the situation, wages and real estate costs in the major Indian cities have gone up rapidly. The BPO firms have responded by moving to second and third-tier cities. One way to further lower costs would be to move to rural areas where wages and real estate costs are even lower.

Murali Vullaganti, the CEO and co-founder of RuralShores, opened the first rural facility in 2008 in Bagepalli, in the state of Karnataka. Vullaganti founded RuralShores after senior management experience with IT, software and BPO companies in India, the United States and Singapore. RuralShores faced some inherent complexities in implementing a business with a social mission in rural India. The biggest challenge was dealing with economies of scale, or rather a lack of economies of scale. Urban BPOs aim to have at least 5,000 seats in an operations center to gain economies of scale. In contrast, many villages in India have a total population of less than 20,000 , and thus are unable to support a large BPO center. RuralShores needed to develop efficient centers with between 200 to 350 seats in order to be viable. The critical infrastructural bottleneck in remote locations for RuralShores was ensuring steady supply of electricity and telecommunication links.

Rural India has high unemployment and RuralShores did not have a problem in recruiting employees. Training new recruits, however, took longer and was more expensive because most of them had poor English language communication skills and limited computer proficiency. Another challenge was providing training on the soft skills of the norms of working 
in a formal work environment - something that was taken for granted with urban recruits. RuralShores also had to take a more lenient approach towards employees. For instance, during the initial days, sometimes entire groups of employees would fail to turn up for work without providing any prior information because there was a wedding in their village. Such transgressions would typically be dealt with severely in urban BPOs. Instead, RuralShores created a standards manual, which was henceforth used during the induction period to train employees about professional standards to be followed.

Instead of having a single large facility, RuralShores organizes its 18 small centers in clusters for the most efficient administration. One local manager manages a center of 200-350 people and a regional manager manages a cluster of about six centers in a region. Technologies such as video conferencing are employed to assist in managing a geographically distributed network of centers. Finance, human resources and payroll functions are centralized as much as possible. Recruiting employees from rural areas provides RuralShores with two advantages. First, the attrition rates of these employees are lower than the attrition rates of urban-based BPO employees: 10 percent per year compared to $40-50$ percent in urban centers. Second, the overall operational costs of running a rural center are lower than urban ones due to lower labor and facilities costs. Because RuralShores is a private for-profit organization, its financial statements are not publicly available, but we did get some financial information from the company, as we will discuss below.

\section{Findings and Diagnosis}

Since the explicit mission of impact sourcing organizations is creating digital jobs for the poor, a straightforward metric to measure the performance of these organizations is the number of jobs created. As can be seen from Figure 1, RuralShores clearly is the most successful of these three organizations in terms of both the number of jobs created and the trend over time. 
Figure 1: Number of Employees for RuralShores, DDD and Samasource

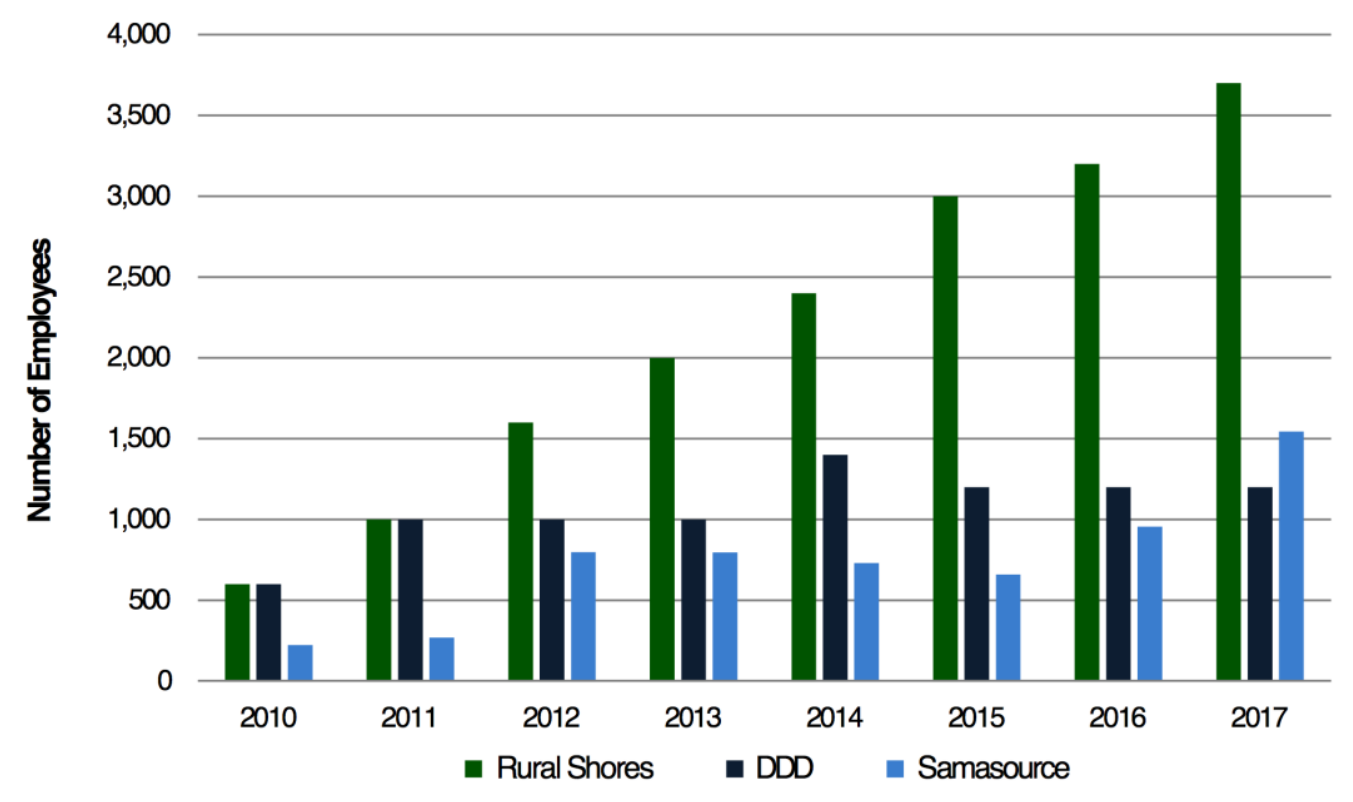

Another metric to measure the performance of these organizations is the operating loss (subsidy) per employee. All three organizations, Samasource, DDD and RuralShores, have had an operating loss in each of the last eight fiscal years. RuralShores alone, however, has only had minor and decreasing losses. Based on analysis of Form 990 filings with the Internal Revenue Service by Samasource and DDD, and financial information provided to us by RuralShores, we calculated the operating loss (subsidy) per employee for the last eight years for the three organizations (see Figure 2). The average loss per employee for the years 2010-17 is about $\$ 3,500$ for Samasource, $\$ 1,500$ for DDD, and $\$ 300$ for RuralShores. To put these numbers in perspective, the average GDP per capita for the countries in which these organizations operate is $\$ 1,200$. It could be argued that Samasource and DDD could achieve greater social impact if they discontinued their operations and just gave money to their beneficiaries. Of course, there is also value in the training and experience provided

by the

not-for-profit

organizations. 


\section{Figure 2: Operating Loss (Subsidies) per Employee for RuralShores, DDD and Samasource}

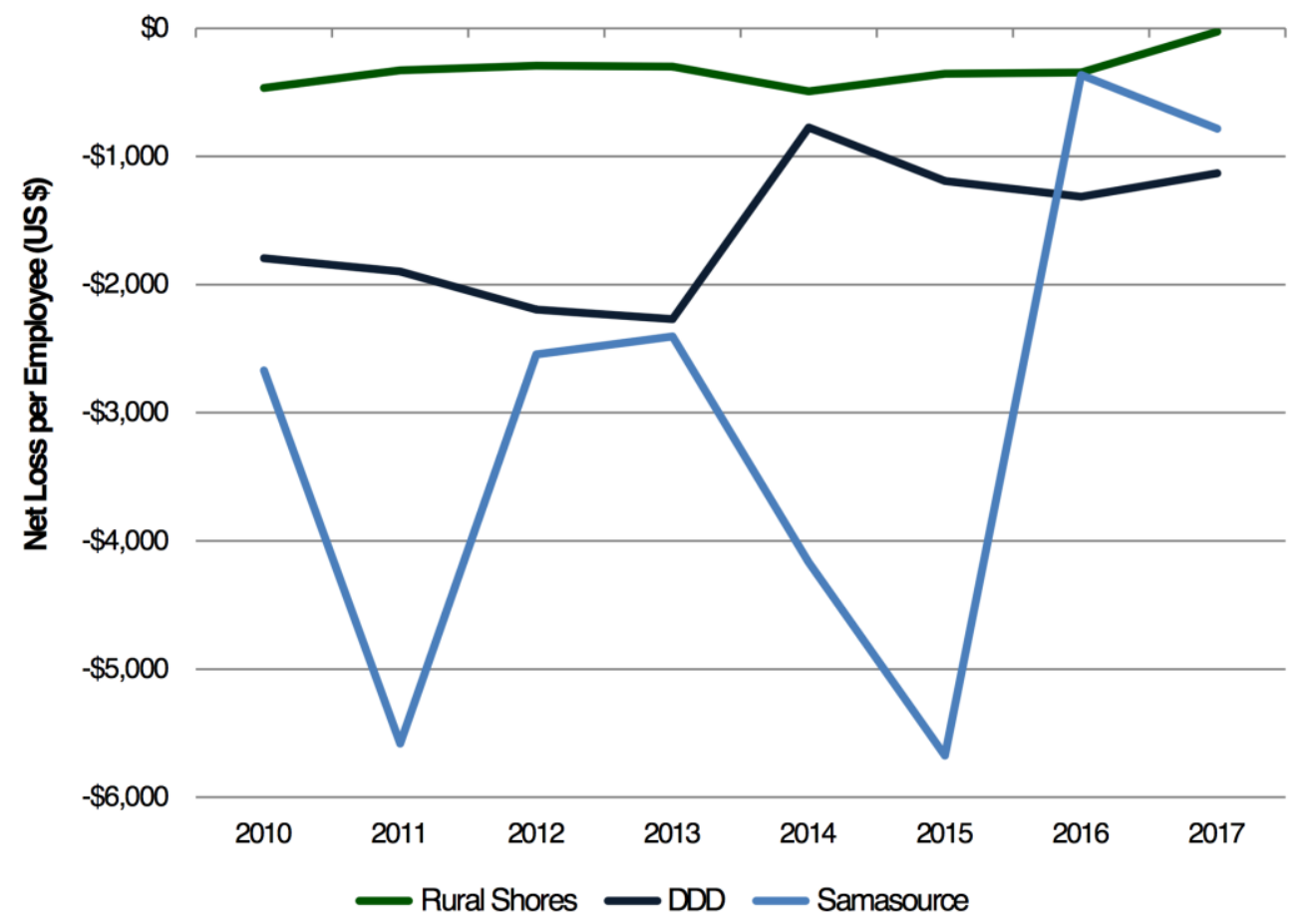

A major topic of discussion on social enterprises focuses on how to scale up and achieve a meaningful impact on large societal problems. The root of the problem is that most social enterprises suffer an operating loss and have to attract grants and donations to cover this loss. Given the paucity of charitable grants and donations, social enterprises often have difficulty attracting capital and therefore cannot sufficiently scale up. The situation is even more dire if we take into account not only the operating costs but also the opportunity cost of capital used (Clyde and Karnani 2015). Private capital seeks economic profits defined as accounting profits minus the opportunity cost of capital used. Modern financial markets can provide virtually unlimited quantities of capital, provided the venture is expected to earn positive economic profits in the future. For a social enterprise to scale up, it needs to focus on and achieve economic profitability.

Not-for-profit social enterprises often have ongoing operational losses and have to continually attract grants and donations to cover these losses, making it difficult to grow significantly and have a major impact. 
For-profit social enterprises usually have operating losses in the early years and cover these losses by raising capital from private investors. These investors behave like venture capitalists and are willing to lose money in the start-up phase because they expect to earn economic profits in the future. Given the enormous size of private capital markets, it is much easier for for-profit enterprises to scale up and achieve significant impact.

This logic of economic profitability applies to impact sourcing organizations also, of course. If impact sourcing organizations could earn economic profits, they would have been able to grow at least as quickly as the BPO industry (10 percent annually globally, and up to 20 percent annually in some countries), and would have created many more jobs for the poor. RuralShores is a for-profit organization funded by private capital whose objective is to earn economic profits. It expects to earn an operating profit in 2020 and is working towards earning economic profits in the near future. It is interesting to note that employment at RuralShores has grown by about 40 percent annually for the last eight years. Of course, if RuralShores does not achieve profitability and self-sustaining viability, then an in-depth re-exploration would be in order.

\section{Strategies for Success}

\section{Economies of Scale}

By far the single most important issue for success as an impact sourcing organization is achieving economies of scale. The research by Kennedy et al. (2013) suggests that the minimum efficient size for a BPO center is about 5,000 employees. None of the impact sourcing organizations has achieved scale even close to this degree. RuralShores only operates centers of size 200-350 employees. It has found a clever solution, however, by operating a cluster of about six centers to achieve greater scale economies in operations and centralizing some administrative functions at the head office to achieve scale economies in overheads. In the private sector, the rationale behind mergers and acquisitions to consolidate an industry is to achieve economies of scale. The investment bank Baird analyzed $220 \mathrm{M} \& \mathrm{~A}$ transactions in the BPO industry in 20092014 and predicts continued consolidation over the next few years (2015). The rarity of mergers and acquisitions between impact sourcing organizations - and other social enterprises - suggests that achieving efficiencies through economies of scale is often underemphasized in the social sector. As an alternative to mergers and acquisitions, impact 
sourcing organizations need to emphasize organic growth to achieve scale economies. Such is the strategy of RuralShores.

Focus

Impact sourcing organizations should focus their resources and activities as much as possible to achieve at least some of the advantages of scale. Both Samasource and DDD are sub-scale to start with and worsen their situation by dispersing their activities over several countries. RuralShores operates only in India: even then it might be well advised to focus its operations in only a few states in India.

Impact sourcing organizations should outsource more activities and focus on their core competencies. RuralShores outsources the construction and maintenance of their rural operations centers to local entrepreneurs. DDD has begun to outsource some of its fundraising proposal writing.

\section{Marketing Costs}

In some businesses, customers are willing to pay higher prices for products/services from social enterprises; an example would be Ben \& Jerry's ice cream. That is not true in most industries, however. As previous research shows that the "market for virtue" is very limited (Vogel 2006). It clearly is not true for the BPO industry: customers outsource business processes primarily to reduce costs and are not willing to pay a premium to impact sourcing organizations. Securing customers and contracts is an ongoing challenge for impact sourcing organizations. Potential clients unfamiliar with the concept of impact sourcing may have concerns about the quality of services delivered given that employees come from the disadvantaged strata of the population.

BPO clients are often located in the USA or other affluent countries. Locating marketing and customer relations in these countries is expensive. Maintaining a head office, even a small one, in San Francisco, as Samasource does, is very costly because of both labor and real estate costs. RuralShores, which is located entirely in India, gets most of its work from large BPO firms who are themselves outsourcing lower end work to other smaller BPO firms or impact sourcing organizations. Relations with the end customer in the USA are managed by the large BPO firm, not RuralShores.

\section{No Frills}

The primary basis of competition in the BPO industry is price that requires an emphasis on low costs. Impact sourcing organizations have the 
potential to exploit their location advantage and achieve 40 percent lower costs than traditional BPO firms (Kubzansky and Nyoro 2011). RuralShores facilities are very basic in terms of construction materials and furnishings. By contrast, Samasource and DDD have offices in upscale USA cities with high overhead costs.

\section{Form Alliances}

Impact sourcing organizations incur high costs for identifying, recruiting and selecting workers because of the poor infrastructure and lack of information. Training disadvantaged workers is costly, and usually requires attention to both soft skills (for example, the norms in a formal work environment, communication skills) and technical skills (such as typing, computer software, English language). One way to reduce these costs is to form alliances with NGOs, local schools and colleges, and other partners interested in helping disadvantaged people. RuralShores relies on local "center partners" to identify and recruit suitable candidates. DDD has partnered with recruiting and training NGO Digital Bridges in Phnom Penh. Samasource collaborates with local delivery centers.

\section{Conclusion}

Poverty is one of the most important social issues globally. The exclusion of hundreds of millions of capable workers from productive activities is an unnecessary waste of economic and human potential. The best way to reduce global poverty and achieve social impact at scale is to understand and remove barriers to the creation of productive jobs. The BPO sector with its 10 percent average global growth rate (up to 20 percent in some countries) and inherent potential to employ low-income individuals around the world provides a pragmatic approach for reducing poverty through employment. A proliferation of impact sourcing organizations has emerged in the last decade to do exactly this.

Our analysis of the sector, including case studies of the three largest impact sourcing organizations, reveals two very different approaches being taken. One approach, illustrated by RuralShores, is to aim to cover economic costs through earned income, aiming to break even and scale organically through market forces. The other approach, illustrated by Samasource and Digital Divide Data, is to rely on charitable donations to cover operating losses. With the second approach, the social impact, growth and scale of the organizations is limited and the cost per job created is high. With most organizations following the second approach, the impact sourcing organization sector as a whole is missing 
out on an important opportunity for significant impact through creating jobs.

To succeed in the very competitive BPO industry, impact sourcing organizations need to focus on cost competitiveness. Our analysis suggested five strategic issues: achieve greater economies of scale; focus by activities and geography; reduce marketing costs; establish no frills facilities; and form alliances. In order for the impact sourcing sector to fulfill its potential to reduce poverty through employment by hiring disadvantaged workers at scale, impact sourcing organizations need to reduce their costs and position themselves as the low-cost providers of choice.

Although poverty has deep, systemic causes, from a management perspective, Impact Sourcing can be one way to address it by creating jobs for the poor that address issues of inequality, growth, social welfare and working conditions.

While this paper has focused on impact sourcing, the results have some broader implications for all social enterprises. The major challenge for the social enterprise sector is how to scale up its impact in addressing large societal problems. So long as the social enterprise sector relies on charitable donations and grants, it is very unlikely to grow and scale up its impact significantly. There just is not enough charity capital available. Private capital is available in virtually unlimited quantities. To attract private capital, however, the social enterprise sector needs to focus on and achieve economic profits (not just accounting profits). The challenge is to design a business model that is likely to yield economic profits while simultaneously fulfilling the social mission of the enterprise. While difficult, it is possible to achieve that combination; RuralShores provides a good example. 


\section{References}

Avasant (2012), Incentives \& Opportunities for Scaling the "Impact Sourcing" Sector, Los Angeles, CA: Avasant / Rockefeller Foundation.

Baird (2015), Transformation of Business Process Outsourcing: Business Models, Technology Enablement and M\&A Themes in the Growing and Fragmented BPO Sector.

Banerjee, Abhijit, Dean Karlan and Jonathan Zinman (2015), "Six Randomized Evaluations of Microcredit: Introduction and Further Steps," American Economic Journal: Applied Economics, 7 (1), 121. https://dx.doi.org/10.1257/app.20140287

Bulloch, Gib, and Jessica Long (2012), Exploring the Value Proposition for Impact Sourcing: The Buyer's Perspective, Accenture, (accessed on January 10, 2019), [https://www.rockefellerfoundation.org/wpcontent/uploads/Exploring-the-Value-Proposition-for-Impact-forImpact-Sourcing.pdf].

Chang, Ha-Joon (2008), Bad Samaritans: The Myth of Free Trade and the Secret History of Capitalism, New York: Bloomsbury Press.

Chertok, Michael and Jeremy Hockenstein (2013), "Sourcing Change: Digital Work Building Bridges to Professional Life," Innovations, September: $185-95$. https:/doi.org/10.1162/INOV a 00172

Clyde, Paul and Aneel Karnani (2015), "Improving Private Sector Impact on Poverty Alleviation: A Cost-Based Taxonomy," California Management Review, $57 \quad$ (2): $20-35$. https://doi.org/10.1525/cmr.2015.57.2.20

Dalberg (2013), Digital Jobs in Africa: Catalyzing Inclusive Opportunities for Youth, New York: Dalberg Global Development Advisors.

de Abreu, Carol, Carolina Vilca and Alexander Bourdeau (2013), Recruitment, Training, and Impact Measurement; a Recommended Approach for Impact Sourcing, Accenture.

Dichter, Thomas W. (2003), Despite Good Intentions: Why Development Assistance to the Third World Has Failed, Amherst: University of Massachusetts Press.

Digital Divide Data (2013), 2013 Annual Report, (accessed on January 10, 2019) [available at: https://www.digitaldividedata.com/corporateinformation].

Easterly, William (2006), The White Man's Burden: Why the West's Efforts to Aid the Rest Have Done So Much III and So Little Good, Oxford: Oxford University Press. 
Friedman, Thomas (2005), The World is Flat. New York: Farrar, Straus and Giroux.

Gino, Francesca and Bradley R. Staats (2012), "Samasource: Give work, not aid," Harvard Business School Case, 9-912-011.

Global Industry Analytics (2017), Business Process Outsourcing (BPO) Global Strategic Business Report, San Jose, CA: Global Industry Analytics.

Grimm, Daniel, Rachna Saxena, Mike Kubzansky and Kurt Dassel (2013), Preparing the Poor and Vulnerable for Digital Jobs: Lessons from Eight Promising Demand-led Training Models. Boston: Monitor Inclusive Markets.

Harji, Karim, Hilary Best, Eme Essien-Lore and Sarah Troup (2013). Digital Jobs: Building Skills for the Future. New York: Rockefeller Foundation.

International Labor Organization (2007), Global Employment Trends: Brief, January.

Karnani, Aneel (2007), "Microfinance Misses Its Mark," Stanford Social Innovation Review, Summer, 34-40.

Karnani, Aneel (2011), Fighting Poverty Together: Rethinking Strategies for Business, Governments, and Civil Society to Reduce Poverty, New York: Palgrave Macmillan.

Kennedy, Robert, Sateen Sheth, Ted London, Ekta Jhaveri and Lea Kilibarda (2013), Impact Sourcing: Assessing the Opportunity for Building a Thriving Industry, Ann Arbor, Michigan: William Davidson Institute.

Kshetri, Nir and Nikhilesh Dholakia (2011), "Offshoring of healthcare services: the case of US-India trade in medical transcription services", Journal of Health Organization and Management, Vol. 25, No.1, pp. 94-107, https://doi.org/10.1108/14777261111116842

Kshetri, Nir and Nikhilesh Dholakia (2009), "Professional and trade associations in a nascent and formative sector of a developing economy: A case study of the NASSCOM effect on the Indian offshoring industry", Journal of International Management, Vol. 15, No. 2, pp. 225-239, https://doi.org/10.1016/j.intman.2008.09.003

Kubzansky, Mike and James Nyoro (2011), Job Creation Through Building the Field of Impact Sourcing, Cambridge, MA: Monitor Inclusive Markets.

Mathew, Anju, Grete Rød, Jaime Villalobos and David Yates (2009). "Digital Divide Data," MIT Sloan Management Case Study.

McKague, Kevin and Christine Oliver (2012), "Enhanced Market Practices: Poverty Alleviation for Poor Producers in Developing Countries," 
California Management Review, 55(1): 98-129. https://doi.org/10.1525/cmr.2012.55.1.98

McKague, Kevin, David Wheeler and Aneel Karnani (2015), "An Integrated Approach to Poverty Alleviation: Roles of the Private Sector, Government and Civil Society," The Business of Social and Environmental Innovation, 129-45, Springer.

NASSCOM (2015), The IT-BPM sector in India: Strategic review 2015, New Delhi, India: National Association of Software and Services Companies.

Prahalad, C. K. (2004), The Fortune at the Bottom of the Pyramid: Eradicating Poverty Through Profits, Upper Saddle River, NJ: Wharton School Publishing.

Rottenberg, Linda and Rhett Morris (2013), "New Research: If You Want to Scale Impact, Put Financial Results First," Harvard Business Review.

Sachs, Jeffrey D. (2005), The End of Poverty: Economic Possibilities for Our Time, New York: Penguin Books.

Stiglitz, Joseph E. (2002). Globalization and Its Discontents, New York: W.W. Norton.

Vogel, David (2006), The Market for Virtue: The Potential and Limits of Corporate Social Responsibility. Washington, DC: Brookings Institution Press.

World Bank (2012), World Development Report 2013: Jobs, Washington, DC: World Bank Group.

World Bank (2013), IFC Jobs Study: Assessing Private Sector Contributions to Job Creation and Poverty Reduction, Washington, DC: World Bank Group. 